\title{
The maternal serological response to intrauterine Ureaplasma sp. infection and prediction of risk of pre-term birth
}

\section{Demelza J. Ireland* and Jeffrey A. Keelan}

School of Women's and Infants' Health, The University of Western Australia, Perth, WA, Australia

\section{Edited by:}

Delmiro Fernandez-Reyes, Brighton

and Sussex Medical School, UK

\section{Reviewed by:}

Lisa Mullen, Brighton and Sussex

Medical School, UK

Florence Burté, Newcastle University, UK

\section{*Correspondence}

Demelza J. Ireland, School of Women's and Infants' Health, Faculty of Medicine, Dentistry and Health Sciences, The University of Western Australia, 35 Stirling Highway, Crawley, WA 6009, Australia e-mail:demelza.ireland@uwa.edu.au
Pre-term birth (PTB) associated with intrauterine infection and inflammation (IUI) is the major cause of early PTB less than 32 weeks of gestation. Ureaplasma spp. are common commensals of the urogenital tract in pregnancy and are the most commonly identified microorganisms in amniotic fluid of pre-term pregnancies. While we have an understanding of the causal relationship between intra-amniotic infection, inflammation and PTB, we are still unable to explain why vaginal Ureaplasma sp. colonization is tolerated in some women but causes PTB in others. It is now known that placental tissues are frequently colonized by bacteria even in apparently healthy pregnancies delivered at term; usually this occurs in the absence of a significant local inflammatory response. It appears, therefore, that the site, nature, and magnitude of the immune response to infiltrating microorganisms are key in determining pregnancy outcome. Some evidence exists that the maternal serological response to Ureaplasma sp. colonization may be predictive of adverse pregnancy outcome, although issues such as the importance of virulence factors (serovars) and the timing, magnitude, and functional consequences of the immune response await clarification. This mini-review discusses the evidence linking the maternal immune response to risk of PTB and the potential applications of maternal serological analysis for predicting obstetric outcome.

Keywords: antibody, immune response, intrauterine infection, pre-term birth, predictive marker, Ureaplasma spp.

\section{INTRODUCTION}

It is estimated globally that approximately 12 million babies are born pre-term each year, making the prevention of pre-term birth (PTB) one of the highest priorities for international obstetric research (1). Intrauterine infection (IUI) and subsequent inflammation of the extra-placental membranes (chorioamnionitis) accounts for approximately $40 \%$ of all spontaneous PTBs and is the major cause of early PTB ( $<32$ weeks of gestation). IUI is typically "silent" (undiagnosed) until the onset of pre-term labor at which point it is often too late for treatment as chorioamnionitis is well established, the risk of fetal inflammatory response syndrome (FIRS) is high (2), and tocolysis is ineffective. Identifying women at risk of infection-associated PTB sufficiently early in pregnancy to allow therapeutic intervention would be a significant advance in the prevention of PTB.

Traditional thinking associates IUI with the ascension of bacteria from cervicovaginal fluid, resulting in intra-amniotic infection and immune stimulation within the otherwise sterile intrauterine environment (3). It is now clear, however, that the placenta and extra-placental membranes can no longer be considered strictly sterile $(4,5)$. Instead, they are home to a unique microbiome of non-pathogenic commensals; the presence of which is normal and not associated with early delivery or adverse pregnancy outcomes $(4,6)$. Histological and immunological analysis of intrauterine tissues and fluids suggests that the nature and magnitude of inflammatory response associated with bacterial colonization may be key in determining obstetric outcome (6-8).

Recent placental microbiological studies have reignited debate regarding the role of differential virulence (9), poly-microbial interactions (10), host genetics (11), and immune factors (12) in determining obstetric outcome. While attention has primarily been placed on defining the local immune response to bacteria within placental tissues, the role and significance of the maternal systemic immune response to the infection has been largely neglected. Yet, studies conducted at the end of the last century strongly suggested that the maternal immune response to commensal microorganisms found in the urogenital tract in pregnancy - in particular the Ureaplasma species - may provide us with important clues as to why some women are at risk of adverse pregnancy outcomes while the majority are not.

In this mini-review, we discuss in detail the somewhat contradictory evidence relating to the presence and nature of maternal antibodies to Ureaplasma sp. and their significance in determining and predicting obstetric outcome. A specific focus is placed on the potential clinical utility of serological analysis in the identification of women at elevated risk of PTB.

\section{UREAPLASMA AND PTB}

Ureaplasma spp. are generally considered commensal microorganisms (13-16) and are classified into two species and 14 
distinct serovars (SV). SV1, SV3, SV6, and SV14 belong to $U$. parvum species and the remaining ten SV to $U$. urealyticum (17). Ureaplasma sp. commonly colonize the urogenital tract of both males and females $(18,19)$. Vaginal colonization rates can vary greatly in non-pregnant women (up to $70 \%)(20,21)$ and women with uncomplicated pregnancies [2.7-70\%; reviewed in Ref. (22)]. Ureaplasma spp. are some of the most frequently identified microorganisms in placental tissues and amniotic fluids (AF) from pre-term deliveries (23-25). Colonization of the placenta with Ureaplasma sp. has been demonstrated to be an independent risk factor for chorioamnionitis [odds ratio (OR), 11.27; 95\% CI, 5.09-24.98] (7). Detection rates in AF vary from $0 \%$ to $19 \%$ in early mid-trimester $(26-28)$, to $2-80 \%$ at pre-term labor $(26,29)$ and $18-100 \%$ with pre-labor premature rupture of membranes (PPROM) (26, 30). A meta-analysis of 22 studies found a significant association between the presence of Ureaplasma sp. in the vagina and AF with PTB (22). However, Ureaplasma sp. colonization in the urogenital tract and AF is a relatively common finding in pregnant women and alone it is not sufficiently predictive of PTB to be clinically useful (8).

The reasons why commensal Ureaplasma sp. cause ascending IUI leading to PTB in only a subset of women are still unknown but are likely to be complex and multifactorial (Figure 1). SV-specific virulence has been proposed as an important determinant of risk of adverse outcome. Of the two Ureaplasma species, U. parvum is the most commonly isolated species from clinical samples (31), with two of its SV - SV3 and SV6 - associated with worse pregnancy outcomes (32-34). Unfortunately, most studies of IUI do not differentiate between Ureaplasma SV so data on the relationship between SV prevalence and risk are lacking. Poly-microbial interactions may also be significant as diagnosis of abnormal bacterial flora or bacterial vaginosis (BV) (i.e., a high Nugent score) is also a risk factor for PTB (35), independent of Ureaplasma sp. colonization status. It is worth noting that poly-microbial colonization of the amniotic cavity is common in pre-term deliveries, with around half of all infected AF containing two or more microorganisms (23). Co-colonization of the vagina with a Ureaplasma sp. and another genital Mycoplasma sp. has been reported to be associated with more severe adverse pregnancy outcomes compared to colonization with a single organism (36). Competence of the cervical barrier to microbial ascension is also likely to play a role in determining risk of PTB. A short cervix in pregnancy has been associated with increased risks of microbial colonization (37) and spontaneous PTB $(38,39)$.

Finally, maternal/fetal immunological tolerance or competence is a likely determinant of obstetric outcome associated

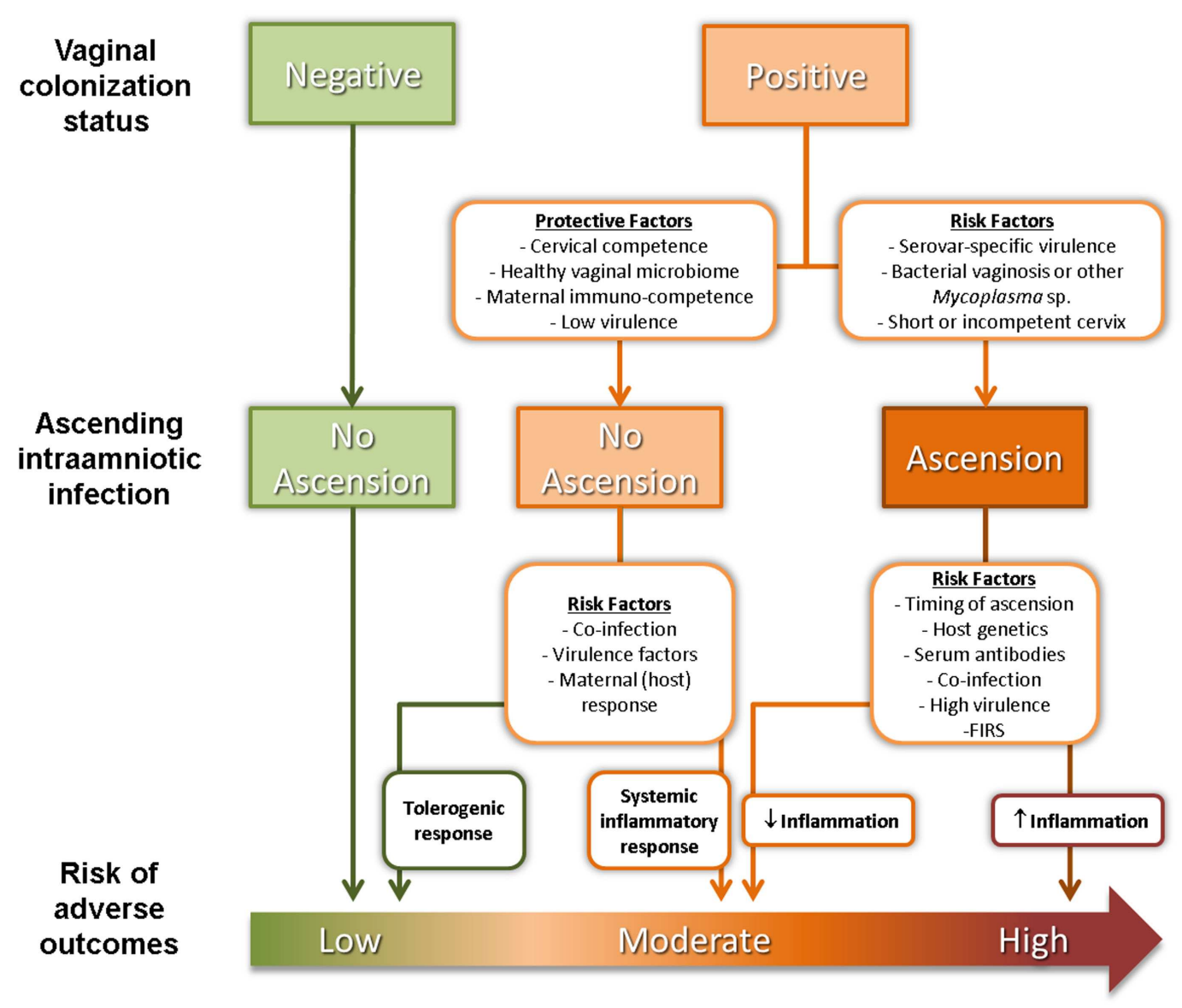

FIGURE 1 | Factors affecting ascension of vaginal Ureaplasma sp. and risk of adverse pregnancy outcomes 
with colonization by Ureaplasma sp. and other microorganisms. Surface-exposed lipoproteins of Ureaplasma sp. activate the pro-inflammatory transcription factor NF- $\kappa$ B through TLR ligation $(40,41)$, although exposure of intrauterine tissues to Ureaplasma sp. does not generally trigger a robust inflammatory response. Nevertheless, intra-amniotic infection with $U$. parvum has been causally linked to chorioamnionitis, FIRS and PTB in animal models (42-44). This is consistent with observations from clinical studies showing that chorioamnionitis/funisitis is more likely in pregnancies infected with Ureaplasma sp. as opposed to other bacteria (7). On the other hand, most women with vaginal colonization and local inflammatory response will not deliver preterm $(24,45)$. Combs, Gravett (8), proposed a model of IUI comprising of five subgroups: (1) microbial colonization plus inflammation (AF IL-6 >11.3 ng/ml); (2) severe inflammation with no detectable microorganisms (AF IL-6 >11.3 ng/ml); (3) mild inflammation with no detectable microorganisms (AF IL-6 of 2.6-11.2 ng/ml); (4) microbial colonization with no inflammation; and (5) absence of infection or inflammation. This more complicated scenario highlights the need to accurately stratify women at risk of PTB associated with IUI.

\section{MATERNAL ANTIBODIES AGAINST UREAPLASMA FOR THE PREDICTION OF PTB}

\section{ANTI-UREAPLASMA SERUM ANTIBODIES IN PATHOGENESIS OR PROTECTION FROM DISEASE}

Specific antibodies may be produced in response to a bacterial infection and detected in the serum (seropositivity). Antibodies act to neutralize bacterial toxins, facilitate opsonization, and together with the complement system work toward clearance of the infection. Antibodies generated against surface-exposed Ureaplasma sp. epitopes have been identified and shown to inhibit Ureaplasma sp. metabolism (46) and support complement mediated Ureaplasma sp. clearance (47) suggestive of a protective effect. Interestingly, individuals with the greatest number/intensity of anti-Ureaplasma antibody bands by immunoblot appeared to have higher Ureaplasma sp. killing ability (47). These data are in contrast with other studies which report that the presence of anti-Ureaplasma antibodies in colonized pregnant women are associated with worse pregnancy outcome [reviewed in Ref. (26); see Anti-Ureaplasma Antibodies as Biomarkers for IUI and PTB below]. In these circumstances, it is likely that seropositivity is pathologic rather than protective, possibly acting via an exacerbation of inflammatory processes triggering PTB (48). This concept is supported by data from a pregnant sheep model of intra-amniotic Ureaplasma sp. infection, in which increased intrauterine inflammation was detected in sheep in which maternal anti-Ureaplasma IgG was also detected (9). Alternatively, it may be the absence of a specific antibody that confers protection from PTB. The key to unraveling this confusion is the identification of antigen-antibody characteristics associated with a given pregnancy outcome to determine whether it is antibody abundance (i.e., titer), nature of the target (i.e., virulence factor), onset of response (time of exposure), or capacity to induce microbial lysis and destruction that is associated with risk of PTB.

\section{ANTI-UREAPLASMA ANTIBODIES AS BIOMARKERS FOR IUI AND PTB}

In the 1980-1990s, several research groups investigated the antibody response to Ureaplasma sp. as a biomarker for intra-amniotic or urogenital infections (49-51). A review on the topic of assessment of antibodies for identification of intra-amniotic infection with Ureaplasma sp. during pregnancy was published in 1994 by Shulamith Horowitz (26). He reviewed the literature and correlated cervical and intra-amniotic Ureaplasma sp. colonization rates with the presence of antibody and pregnancy outcome. Specifically, he found that a greater percentage of women had adverse pregnancy outcomes if they had positive Ureaplasma sp. AF cultures and elevated serum anti-Ureaplasma antibody titers at either genetic amniocentesis, or pre-term labor with/without PPROM (defined as fetal loss, stillbirth, pre-term delivery, or low birth weight) (Figure 2A) (26). Odds ratios and relative risks for adverse pregnancy outcome in culture-positive $(\mathrm{C}+)$ /antibody-positive $(\mathrm{Ab}+)$ women vs. $\mathrm{C}+$ /antibody-negative $(\mathrm{Ab}-)$ women were calculated based on these data and are presented in Figure 2B. Despite some discrepancy between studies, the detection of anti-Ureaplasma IgG in maternal sera together with AF colonization was predictive of an increased risk of developing pregnancy complications [OR: 81.00 at genetic amniocentesis $(p=0.04)$; OR: $24.56(p=0.04)$; and RR: $2.31(p=0.02)$ at PPROM]. Despite these encouraging findings, this line of research has not matured over the proceeding decades for the reasons outline below.

\section{FACTORS THAT HAVE LIMITED THE CLINICAL TRANSLATION OF MATERNAL ANTIBODY DETECTION FOR PREDICTION OF PTB}

Unfortunately, routine amniocentesis for the purpose of diagnosing intra-amniotic colonization with Ureaplasma sp. is not clinically feasible due to the procedure-associated risk of spontaneous miscarriage (RR 1.60; 95\% CI 1.02-2.52) (52). Furthermore, the rates of Ureaplasma sp. colonization of AF in mid pregnancy are actually very low $(22,26,27)$. As such, consideration has been given to the ability of maternal antibodies alone to stratify pregnant women for risk of PTB.

\section{SEROCONVERSION IN RESPONSE TO UREAPLASMA IS COMMON}

Early studies varied in their reported rates of seroconversion. ELISA based studies reported anti-Ureaplasma IgG seropositivity rates of $50-85 \%$ in culture-positive individuals and $6-15 \%$ in culture-negative individuals $(46,53,54)$. However, these studies reported positive cutoffs based on maximum detection in culture-negative cohorts, assuming culture-negative individuals to be seronegative $(53,54)$. Others have since shown by immunoblot that seroconversion is more common, with greater than $80 \%$ of sera from healthy non-pregnant individuals (47) recognizing at least one Ureaplasma sp. antigen (IgG response). As the seroconversion rate is high in both colonized and non-colonized individuals, several studies used a method of serum dilution for assigning positivity to sera with elevated titers $(46,55)$. It is still unclear whether differences between patients with slightly elevated vs. very high levels of antibodies are clinically significant. As colonization is so common, it is most likely that seropositivity in non-colonized individuals represents a persistent antibody to a cleared infection. Nevertheless, high seroconversion rates mean that detection of 


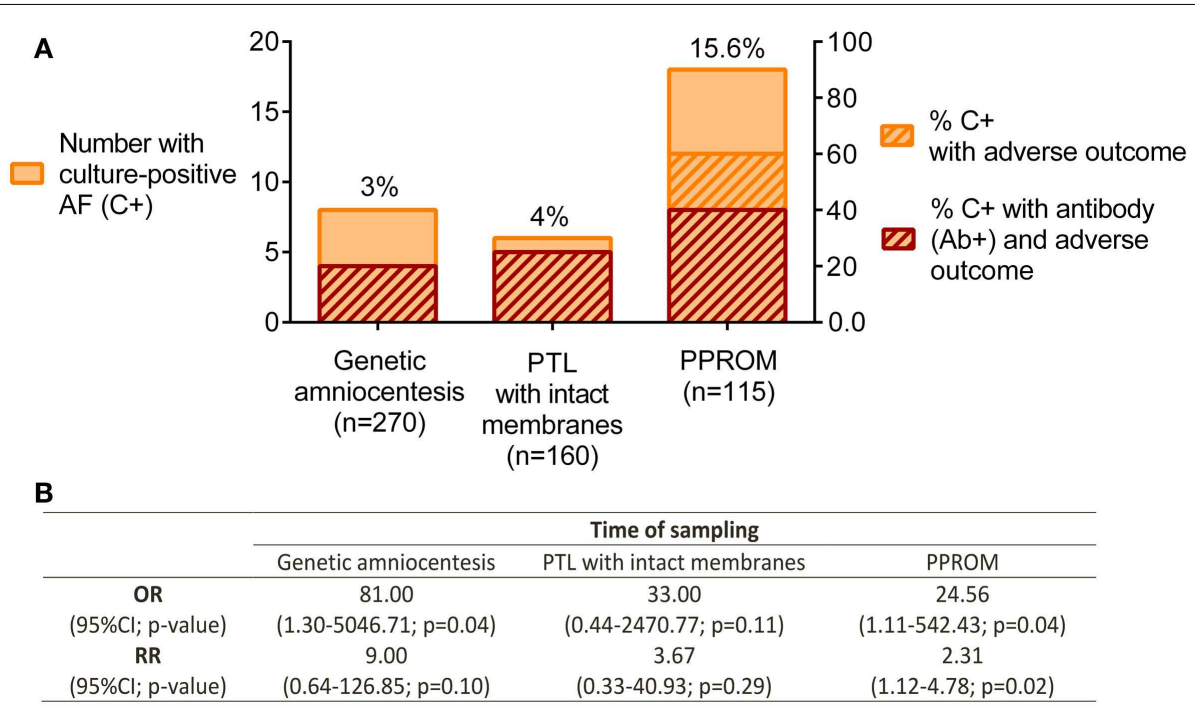

FIGURE 2 | Pregnancy outcome in relation to culture-positive (C+) AF and anti-Ureaplasma antibodies $(\mathrm{Ab}+)$ in maternal serum.

(A) Ureaplasma sp. detected by culture technique. Antibodies determined by ELISA and semi-quantitation of antibody titer; adverse pregnancy outcome defined as fetal loss, stillbirth, pre-term delivery, and low birth weight. Genetic amniocentesis was performed at 16-20 weeks of gestation; no gestational age provided for the PTL and PPROM groups. (B) Odds ratios (OR) and relative risks (RR) for adverse pregnancy outcome in culture-positive/antibody-positive $\left(C^{+} A b^{+}\right)$vs. $C^{+} A b^{-}$were calculated for each group. Data extracted and adapted from Horowitz et al. (26).
IgG antibody responses to whole cell lysates or isolated membrane antigens is unlikely to be clinically useful.

\section{SEROVAR-SPECIFIC UREAPLASMA ANTIGENS AND CROSS-REACTIVITY} U. parvum SV3 and SV6 are most commonly associated with worse pregnancy outcome (32-34). The possibility of a SV-specific antibody response to Ureaplasma sp. was proposed following the identification of apparent SV-specific antigens. For example, an $85 \mathrm{kDa}$ protein in SV1, a $71 \mathrm{kDa}$ protein from SV3, $61 \mathrm{kDa}$ and $55 \mathrm{kDa}$ proteins from SV6, and an $88 \mathrm{kDa}$ protein from SV14 have all been identified (56). However, there is extensive antigen cross-reactivity among all SV with the evidence for SV specificity strongest in individual cases. It is likely that the multiple-banded antigen (MBA) is a key virulence factor for Ureaplasma sp. (57), containing both SV-specific and conserved/cross-reactive epitopes (58). The MBA, a surface-expressed diacylated lipoprotein, is recognized by TLRs 1, 2, 6 (40), and 9 (41) and has a molecular weight of approximately $70-90 \mathrm{kDa}(59)$, but migrates as a symmetrical ladder pattern between 55 and $75 \mathrm{kDa}$ on immunoblot due to conformational folding (58). The $m b a$ gene exists as a single copy within the Ureaplasma sp. genome (60). The precise immunogenic MBA epitopes are still unknown but are considered to be within the size-variable and surface-exposed C-terminal region (58). Mutations in the mba gene have been proposed to play an important role in helping the organism evade the host immune system (60) with multiple mechanisms proposed (58-61).

Serum from Ureaplasma sp. colonized individuals detect multiple and likely closely related antigens forming the ladder seen on immunoblots. The identity of specific immunodominant epitopes and their role in differential pathogenesis in pregnancy remains unclear and is further complicated by the variability of the MBA. A number of cases where mother-fetus dyads appeared to be colonized with different SV and generated different antibody responses (as determined by ELISA) have been observed (62). It needs to be remembered that Ureaplasma spp. are fastidious organisms, and without careful collection and appropriate culture protocols their presence may have been missed (63). Molecular methods, in combination with routine culture, are now preferred for the detection and speciation of Ureaplasma sp. in clinical samples (64).

The lack of robust and reliable techniques to differentiate between SV, the diversity of responses among individuals and the cross-reactivity between SV have significantly compromised the ability to use antibody responses beyond the simple determination of seroconversion. Clarification of the relationship between SV-related antigens, microbial virulence, and differential systemic immune responses will be required to resolve the present impasse.

\section{FETAL ANTIBODY RESPONSES TO UREAPLASMA AND OBSTETRIC OUTCOME}

While our emphasis has been on the maternal immune response as a determinant of obstetric outcome, fetal systemic responses can undoubtedly contribute to progression to PTB (65). In utero exposure to Ureaplasma sp. is commonly associated with increased incidence of neonatal complications including bronchopulmonary dysplasia, intraventricular hemorrhage, necrotizing enterocolitis, and pneumonia (66-69). Fetal production of antibody against Ureaplasma sp. has been reported (70-72), with antibody detected at birth in neonates as young as 22-27 weeks of gestation. Moreover, antibody titer appears to correlate negatively with neonatal outcome. IgM has been detected in the fetus/neonate consistent with an initial stage of immune recognition (62). In the sheep model, anti-Ureaplasma IgG has also been detected in fetal serum, with one case reported where the antibodies in maternal and 
fetal sera recognized different antigens (9). Furthermore, fetuses which developed systemic Ureaplasma sp. infection [culturepositive cerebrospinal fluid (CSF)] were found in ewes with the lowest numbers of MBA variants in AF and the highest monocyte count in the chorioamnion (61). Thus, monitoring maternal responses alone may fail to identify the fetuses at most risk in utero. Unfortunately, acquiring blood antenatally for determination of fetal seroconversion is not a practical approach for assessing risk of PTB.

\section{CELLULAR RESPONSES TO UREAPLASMA}

Ureaplasma sp. have been shown to stimulate pro-inflammatory responses in fetal membranes (73), choriodecidual explants (74), and preterm and term cord blood (75). However, studies of white blood cell responses to Ureaplasma sp. in pregnancy have not proven to be useful to date, with no differences in responsiveness observed in leukocytes from women at risk of PTB compared to those with normal pregnancies (12). Reyes et al. explained differential pathogenesis of Ureaplasma sp. in urinary tract infections (UTIs) by demonstrating the presence of two distinct immune cell profiles (76). Asymptomatic UTIs were characterized by minimal monocytic and lymphocytic infiltration, less tissue damage and increased IFN- $\gamma$, while complicated UTIs were associated with greater concentrations of pro-inflammatory cytokines, extensive inflammation and predominantly a neutrophilic response. No comparable data from pregnant women have been published to date. Recently, unconventional lipid antigens such as those present in Ureaplasma sp. $(9,57)$, and microbe-derived vitamin B metabolites (77), have also been shown to stimulate $\mathrm{T}$ cell responses vital for microbial clearance $(78,79)$. However, the role of these unconventional T cells in the response to Ureaplasma sp. in the context of pregnancy immunity and PTB risk remains unknown and the role of the systemic immune cell responses to Ureaplasma sp. exposure in pregnancy remains relatively unexplored.

\section{CONCLUDING REMARIS}

Despite advances in our understanding of the causal relationships between intrauterine infection and PTB, major research questions remain unanswered: is there a subpopulation of patients in which Ureaplasma sp. colonization correlates with worse disease outcome? Does the site of colonization determine disease outcome? Are there pathogenic and non-pathogenic SV determining disease outcome? Is there a specific aspect of the maternal immune response to Ureaplasma sp. infection that influences risk of PTB?

Research on specific Ureaplasma sp. SV and virulence factors have failed to yield conclusive results. Despite the earlier clinical promise of antibody-based predictive approaches $(26,62)$, the assessment of maternal or fetal seropositivity to identify women for prophylactic treatment has not made it into clinical practice. It is unclear when and where exposure to Ureaplasma sp. antigens takes place in pregnancy and when/how commensal colonization becomes an infection. As such, it is difficult to define the role of antibodies in pathogenesis. Antibody cross-reactivity among the Ureaplasma SV and lack of stringent proof of epitope specificity have also limited attempts to use an individual's antibody response to make a SV-specific diagnosis of infection or predict an outcome.
Before an antibody-based immunological test can be considered as part of a routine antenatal screen, future studies must address technical and scientific issues surrounding the detection and antigen characterization of antibodies to Ureaplasma sp. $(41,46,47,54,58)$. Key issues to be addressed include: (i) need for the identification of the colonizing SV; (ii) requirement for the detection of a SV-specific or global antibody response; (iii) characterization of immunodominant epitopes; (iv) defining the difference between commensal colonization and infection; (v) determining when and where Ureaplasma sp. are first immunologically detected; and (vi) characterizing the kinetics and magnitude of the antibody response in relation to pregnancy outcome. Based on current knowledge, it seems that the detection and measurement of uncharacterized maternal antibodies against Ureaplasma sp. has limited predictive value for identifying women at elevated risk of infection-driven PTB.

\section{ACKNOWLEDGMENTS}

The funding support of the Women and Infants Research Foundation (WIRF), the Channel 7 Telethon Trust and the National Health and Medical Research Council (NHMRC) of Australia (grant \#APP 1024467) are gratefully acknowledged.

\section{REFERENCES}

1. Romero R, Espinoza J, Chaiworapongsa T, Kalache K. Infection and prematurity and the role of preventive strategies. Semin Neonatol (2002) 7(4):259-74 doi:10.1053/siny.2002.0121

2. DiGiulio DB, Romero R, Kusanovic JP, Gomez R, Kim CJ, Seok KS, et al. Prevalence and diversity of microbes in the amniotic fluid, the fetal inflammatory response, and pregnancy outcome in women with preterm pre-labor rupture of membranes. Am J Reprod Immunol (2010) 64(1):38-57. doi:10.1111/j.16000897.2010.00830.x

3. Kim MJ, Romero R, Gervasi MT, Kim JS, Yoo W, Lee DC, et al. Widespread microbial invasion of the chorioamniotic membranes is a consequence and not a cause of intra-amniotic infection. Lab Investigat (2009) 89(8):924-36. doi:10.1038/labinvest.2009.49

4. Aagaard K, Ma J, Antony KM, Ganu R, Petrosino J, Versalovic J. The placenta harbors a unique microbiome. Sci Transl Med (2014) 6(237):237ra65. doi:10.1126/scitranslmed.3008599

5. Steel JH, Malatos S, Kennea N, Edwards AD, Miles L, Duggan P, et al. Bacteria and inflammatory cells in fetal membranes do not always cause preterm labor. Pediatr Res (2005) 57(3):404-11. doi:10.1203/01.PDR.0000153869.96337.90

6. Stout MJ, Conlon B, Landeau M, Lee I, Bower C, Zhao Q, et al. Identification of intracellular bacteria in the basal plate of the human placenta in term and preterm gestations. Am J Obstet Gynecol (2013) 208(3):e1-7. doi:10.1016/j.ajog.2013.01.018

7. Namba F, Hasegawa T, Nakayama M, Hamanaka T, Yamashita T, Nakahira $\mathrm{K}$, et al. Placental features of chorioamnionitis colonized with Ureaplasma species in preterm delivery. Pediatr Res (2010) 67(2):166-72. doi:10.1203/PDR. 0b013e3181c6e58e

8. Combs CA, Gravett M, Garite TJ, Hickok DE, Lapidus J, Porreco R, et al. Amniotic fluid infection, inflammation, and colonization in preterm labor with intact membranes. Am J Obstet Gynecol (2014) 210(2):e1-15. doi:10.1016/j.ajog.2013. 11.032

9. Dando SJ, Nitsos I, Kallapur SG, Newnham JP, Polglase GR, Pillow JJ, et al. The role of the multiple banded antigen of Ureaplasma parvum in intra-amniotic infection: major virulence factor or decoy? PLoS One (2012) 7(1):e29856. doi:10.1371/journal.pone.0029856

10. Racicot K, Cardenas I, Wunsche V, Aldo P, Guller S, Means RE, et al. Viral infection of the pregnant cervix predisposes to ascending bacterial infection. J Immunol (2013) 191(2):934-41. doi:10.4049/jimmunol.1300661

11. Heng YJ, Pennell CE, Chua HN, Perkins JE, Lye SJ. Whole blood gene expression profile associated with spontaneous preterm birth in women with threatened preterm labor. PLoS One (2014) 9(5):e96901. doi:10.1371/journal.pone.0096901 
12. Peltier MR, Faux DS, Hamblin SD, Silver RM, Esplin MS. Cytokine production by peripheral blood mononuclear cells of women with a history of preterm birth. J Reprod Immunol (2010) 84(1):111-6. doi:10.1016/j.jri.2009.10.002

13. Waites KB, Schelonka RL, Xiao L, Grigsby PL, Novy MJ. Congenital and opportunistic infections: Ureaplasma species and Mycoplasma hominis. Semin Fetal Neonatal Med (2009) 14(4):190-9. doi:10.1016/j.siny.2008.11.009

14. DiGiulio DB, Romero R, Amogan HP, Kusanovic JP, Bik EM, Gotsch F, et al. Microbial prevalence, diversity and abundance in amniotic fluid during preterm labor: a molecular and culture-based investigation. PLoS One (2008) 3(8):e3056. doi:10.1371/journal.pone.0003056

15. Onderdonk AB, Hecht JL, McElrath TF, Delaney ML, Allred EN, Leviton A, et al. Colonization of second-trimester placenta parenchyma. Am J Obstet Gynecol (2008) 199(1):e1-10. doi:10.1016/j.ajog.2007.11.068

16. Romero R, Espinoza J, Goncalves LF, Kusanovic JP, Friel L, Hassan S. The role of inflammation and infection in preterm birth. Semin Reprod Med (2007) 25(1):21-39. doi:10.1055/s-2006-956773

17. Robertson JA, Stemke GW. Expanded serotyping scheme for Ureaplasma urealyticum strains isolated from humans. J Clin Microbiol (1982) 15(5):873-8.

18. Schelonka RL, Waites KB. Ureaplasma infection and neonatal lung disease. Semin Perinatol (2007) 31(1):2-9. doi:10.1053/j.semperi.2007.01.001

19. McIver CJ, Rismanto N, Smith C, Naing ZW, Rayner B, Lusk MJ, et al. Multiplex PCR testing detection of higher-than-expected rates of cervical Mycoplasma, Ureaplasma, and Trichomonas and viral agent infections in sexually active Australian women. J Clin Microbiol (2009) 47(5):1358-63. doi:10.1128/JCM. 01873-08

20. Hunjak B, Sabol I, Vojnovic G, Fistonic I, Erceg AB, Persic Z, et al. Ureaplasma urealyticum and Ureaplasma parvum in women of reproductive age. Arch Gynecol Obstet (2014) 289(2):407-12. doi:10.1007/s00404-013-2980-z

21. Agbakoba NR, Adetosoye AI, Adewole IF. Presence of Mycoplasma and Ureaplasma species in the vagina of women of reproductive age. West Afr J Med (2007) 26(1):28-31. doi:10.4314/wajm.v26i1.28299

22. Capoccia R, Greub G, Baud D. Ureaplasma urealyticum, Mycoplasma hominis and adverse pregnancy outcomes. Curr Opin Infect Dis (2013) 26(3):231-40. doi:10.1097/QCO.0b013e328360db58

23. DiGiulio DB. Diversity of microbes in amniotic fluid. Semin Fetal Neonatal Med (2012) 17(1):2-11. doi:10.1016/j.siny.2011.10.001

24. Perni SC, Vardhana S, Korneeva I, Tuttle SL, Paraskevas LR, Chasen ST, et al. Mycoplasma hominis and Ureaplasma urealyticum in midtrimester amniotic fluid: association with amniotic fluid cytokine levels and pregnancy outcome. Am J Obstet Gynecol (2004) 191(4):1382-6. doi:10.1016/j.ajog.2004.05.070

25. Breugelmans M, Vancutsem E, Naessens A, Laubach M, Foulon W. Association of abnormal vaginal flora and Ureaplasma species as risk factors for preterm birth: a cohort study. Acta Obstet Gynecol Scand (2010) 89(2):256-60. doi:10.3109/00016340903418769

26. Horowitz S, Mazor M, Horowitz J, Glezerman M. Antibodies as reagents for identification of intraamniotic infection with Ureaplasma urealyticum during pregnancy. Isr J Med Sci (1994) 30(5-6):450-4.

27. Payne MS, Feng Z, Li S, Doherty DA, Xu B, Li J, et al. Second trimester amniotic fluid cytokine concentrations, Ureaplasma sp. colonisation status and sexual activity as predictors of preterm birth in Chinese and Australian women. BMC Pregnancy Childbirth (2014) 14:340. doi:10.1186/1471-2393-14-340

28. Oh KJ, Lee SE, Jung H, Kim G, Romero R, Yoon BH. Detection of Ureaplasmas by the polymerase chain reaction in the amniotic fluid of patients with cervical insufficiency. J Perinat Med (2010) 38(3):261-8. doi:10.1515/JPM.2010.040

29. Yoon BH, Chang JW, Romero R. Isolation of Ureaplasma urealyticum from the amniotic cavity and adverse outcome in preterm labor. Obstet Gynecol (1998) 92(1):77-82. doi:10.1016/S0029-7844(98)00122-7

30. Yoon BH, Romero R, Park JS, Chang JW, Kim YA, Kim JC, et al. Microbial invasion of the amniotic cavity with Ureaplasma urealyticum is associated with a robust host response in fetal, amniotic, and maternal compartments. Am J Obstet Gynecol (1998) 179(5):1254-60. doi:10.1016/S0002-9378(98) 70142-5

31. Waites KB, Katz B, Schelonka RL. Mycoplasmas and Ureaplasmas as neonatal pathogens. Clin Microbiol Rev (2005) 18(4):757-89. doi:10.1128/CMR.18.4. 757-789.2005

32. Naessens A, Foulon W, Breynaert J, Lauwers S. Serotypes of Ureaplasma urealyticum isolated from normal pregnant women and patients with pregnancy complications. J Clin Microbiol (1988) 26(2):319-22.
33. Robertson JA, Honore LH, Stemke GW. Serotypes of Ureaplasma urealyticum in spontaneous abortion. Pediatr Infect Dis (1986) 5(6 Suppl):S270-2. doi:10. 1097/00006454-198611010-00014

34. Xiao L, Paralanov V, Glass JI, Duffy LB, Robertson JA, Cassell GH, et al. Extensive horizontal gene transfer in Ureaplasmas from humans questions the utility of serotyping for diagnostic purposes. J Clin Microbiol (2011) 49(8):2818-26. doi:10.1128/JCM.00637-11

35. Lee SE, Romero R, Kim EC, Yoon BH. A high Nugent score but not a positive culture for genital Mycoplasmas is a risk factor for spontaneous preterm birth. J Maternal Fetal Neonatal Med (2009) 22(3):212-7. doi:10.1080/ 14767050802616994

36. Kwak DW, Hwang HS, Kwon JY, Park YW, Kim YH. Co-infection with vaginal Ureaplasma urealyticum and Mycoplasma hominis increases adverse pregnancy outcomes in patients with preterm labor or preterm premature rupture of membranes. J Maternal Fetal Neonatal Med (2014) 27(4):333-7. doi:10.3109/14767058.2013.818124

37. Lee SE, Romero R, Park CW, Jun JK, Yoon BH. The frequency and significance of intraamniotic inflammation in patients with cervical insufficiency. Am J Obstet Gynecol (2008) 198(6):e1-8. doi:10.1016/j.ajog.2007.11.047

38. Romero R, Yeo L, Miranda J, Hassan SS, Conde-Agudelo A, Chaiworapongsa T. A blueprint for the prevention of preterm birth: vaginal progesterone in women with a short cervix. J Perinat Med (2013) 41(1):27-44. doi:10.1515/jpm-20120272

39. Guimaraes Filho HA, Araujo Junior E, Pires CR, Nardozza LM, Moron AF. Short cervix syndrome: current knowledge from etiology to the control. Arch Gynecol Obstet (2013) 287(4):621-8. doi:10.1007/s00404-013-2740-0

40. Shimizu T, Kida Y, Kuwano K. Ureaplasma parvum lipoproteins, including MB antigen, activate NF-\{kappa\}B through TLR1, TLR2 and TLR6. Microbiology (2008) 154(Pt 5):1318-25. doi:10.1099/mic.0.2007/016212-0

41. Triantafilou M, De Glanville B, Aboklaish AF, Spiller OB, Kotecha S, Triantafilou K. Synergic activation of toll-like receptor (TLR) 2/6 and 9 in response to Ureaplasma parvum \& urealyticum in human amniotic epithelial cells. PLoS One (2013) 8(4):e61199. doi:10.1371/journal.pone.0061199

42. Novy MJ, Duffy L, Axthelm MK, Sadowsky DW, Witkin SS, Gravett MG, et al. Ureaplasma parvum or Mycoplasma hominis as sole pathogens cause chorioamnionitis, preterm delivery, and fetal pneumonia in rhesus macaques. Reprod Sci (2009) 16(1):56-70. doi:10.1177/1933719108325508

43. Collins JJ, Kallapur SG, Knox CL, Nitsos I, Polglase GR, Pillow JJ, et al. Inflammation in fetal sheep from intra-amniotic injection of Ureaplasma parvum. Am J Physiol Lung Cell Mol Physiol (2010) 299(6):L852-60. doi:10.1152/ajplung. 00183.2010

44. Normann E, Lacaze-Masmonteil T, Eaton F, Schwendimann L, Gressens P, Thebaud B. A novel mouse model of Ureaplasma-induced perinatal inflammation: effects on lung and brain injury. Pediatr Res (2009) 65(4):430-6. doi:10.1203/PDR.0b013e31819984ce

45. Gerber S, Vial Y, Hohlfeld P, Witkin SS. Detection of Ureaplasma urealyticum in second-trimester amniotic fluid by polymerase chain reaction correlates with subsequent preterm labor and delivery. J Infect Dis (2003) 187(3):518-21. doi:10.1086/368205

46. Brown MB, Cassell GH, Taylor-Robinson D, Shepard MC. Measurement of antibody to Ureaplasma urealyticum by an enzyme-linked immunosorbent assay and detection of antibody responses in patients with nongonococcal urethritis. J Clin Microbiol (1983) 17(2):288-95.

47. Beeton ML, Daha MR, El-Shanawany T, Jolles SR, Kotecha S, Spiller OB. Serum killing of Ureaplasma parvum shows serovar-determined susceptibility for normal individuals and common variable immuno-deficiency patients. Immunobiology (2012) 217(2):187-94. doi:10.1016/j.imbio.2011.07.009

48. Horowitz S, Horowitz J, Mazor M, Porath A, Glezerman M. Ureaplasma urealyticum cervical colonization as a marker for pregnancy complications. Int J Gynaecol Obstetr (1995) 48(1):15-9. doi:10.1016/0020-7292(94)02236-4

49. Gallo D, Dupuis KW, Schmidt NJ, Kenny GE. Broadly reactive immunofluorescence test for measurement of immunoglobulin $\mathrm{M}$ and $\mathrm{G}$ antibodies to Ureaplasma urealyticum in infant and adult sera. J Clin Microbiol (1983) 17(4):614-8.

50. Gibbs RS, Cassell GH, Davis JK, St Clair PJ. Further studies on genital Mycoplasmas in intra-amniotic infection: blood cultures and serologic response. Am J Obstet Gynecol (1986) 154(4):717-26. doi:10.1016/00029378(86)90442-4 
51. Lin JS. Human mycoplasmal infections: serologic observations. Rev Infect Dis (1985) 7(2):216-31. doi:10.1093/clinids/7.2.216

52. Alfirevic Z, Sundberg K, Brigham S. Amniocentesis and chorionic villus sampling for prenatal diagnosis. Cochrane Database Systematic Rev (2003) 3:CD003252. doi:10.1002/14651858.CD003252

53. Liepmann MF, Wattre P, Dewilde A, Papierok G, Delecour M. Detection of antibodies to Ureaplasma urealyticum in pregnant women by enzyme-linked immunosorbent assay using membrane antigen and investigation of the significance of the antibodies. J Clin Microbiol (1988) 26(10):2157-60.

54. Vancutsem E, Echahidi F, Van Geel K, Muyldermans G, Soetens O, Naessens A. Production of recombinant antigens of Ureaplasma parvum serotypes 3 and 6 for development of a serological assay. Clin Vaccine Immunol (2008) 15(3):447-51. doi:10.1128/CVI.00379-07

55. Horowitz S, Mazor M, Horowitz J, Porath A, Glezerman M. Antibodies to Ureaplasma urealyticum in women with intraamniotic infection and adverse pregnancy outcome. Acta Obstet Gynecol Scand (1995) 74(2):132-6. doi:10.3109/ 00016349509008922

56. Watson HL, Blalock DK, Cassell GH. Variable antigens of Ureaplasma urealyticum containing both serovar-specific and serovar-cross-reactive epitopes. Infect Immun (1990) 58(11):3679-88.

57. Uchida K, Nakahira K, Mimura K, Shimizu T, De Seta F, Wakimoto T, et al. Effects of Ureaplasma parvum lipoprotein multiple-banded antigen on pregnancy outcome in mice. J Reprod Immunol (2013) 100(2):118-27. doi:10.1016/ j.jri.2013.10.001

58. Zheng X, Teng LJ, Watson HL, Glass JI, Blanchard A, Cassell GH. Small repeating units within the Ureaplasma urealyticum MB antigen gene encode serovar specificity and are associated with antigen size variation. Infect Immun (1995) 63(3):891-8.

59. Monecke S, Helbig JH, Jacobs E. Phase variation of the multiple banded protein in Ureaplasma urealyticum and Ureaplasma parvum. Int J Med Microbiol (2003) 293(2-3):203-11. doi:10.1078/1438-4221-00239

60. Paralanov V, Lu J, Duffy LB, Crabb DM, Shrivastava S, Methe BA, et al. Comparative genome analysis of 19 Ureaplasma urealyticum and Ureaplasma parvum strains. BMC Microbiol (2012) 12:88. doi:10.1186/1471-2180-12-88

61. Knox CL, Dando SJ, Nitsos I, Kallapur SG, Jobe AH, Payton D, et al. The severity of chorioamnionitis in pregnant sheep is associated with in vivo variation of the surface-exposed multiple-banded antigen/gene of Ureaplasma parvum. Biol Reprod (2010) 83(3):415-26. doi:10.1095/biolreprod.109.083121

62. Quinn PA, Li HC, Th'ng C, Dunn M, Butany J. Serological response to Ureaplasma urealyticum in the neonate. Clin Infect Dis (1993) 17(Suppl 1):S136-43. doi:10.1093/clinids/17.Supplement_1.S136

63. Waites KB, Xiao L, Paralanov V, Viscardi RM, Glass JI. Molecular methods for the detection of Mycoplasma and Ureaplasma infections in humans: a paper from the 2011 William Beaumont Hospital Symposium on molecular pathology. JMol Diagnost (2012) 14(5):437-50. doi:10.1016/j.jmoldx.2012.06.001

64. Payne MS, Tabone T, Kemp MW, Keelan JA, Spiller OB, Newnham JP. Highresolution melt PCR analysis for genotyping of Ureaplasma parvum isolates directly from clinical samples. J Clin Microbiol (2014) 52(2):599-606. doi:10.1128/JCM.03036-13

65. Chaiworapongsa T, Romero R, Kim JC, Kim YM, Blackwell SC, Yoon BH, et al. Evidence for fetal involvement in the pathologic process of clinical chorioamnionitis. Am J Obstet Gynecol (2002) 186(6):1178-82. doi:10.1067/mob.2002. 124042

66. Waites KB, Rudd PT, Crouse DT, Canupp KC, Nelson KG, Ramsey C, et al. Chronic Ureaplasma urealyticum and Mycoplasma hominis infections of central nervous system in preterm infants. Lancet (1988) 1(8575-6):17-21. doi:10. 1016/S0140-6736(88)91002-1

67. Kasper DC, Mechtler TP, Bohm J, Petricevic L, Gleiss A, Spergser J, et al. In utero exposure to Ureaplasma spp. is associated with increased rate of bronchopulmonary dysplasia and intraventricular hemorrhage in preterm infants. J Perinat Med (2011) 39(3):331-6. doi:10.1515/JPM.2011.022

68. Cassell GH, Waites KB, Crouse DT, Rudd PT, Canupp KC, Stagno S, et al. Association of Ureaplasma urealyticum infection of the lower respiratory tract with chronic lung disease and death in very-low-birth-weight infants. Lancet (1988) 2(8605):240-5. doi:10.1016/S0140-6736(88)92536-6

69. Okogbule-Wonodi AC, Gross GW, Sun CC, Agthe AG, Xiao L, Waites KB, et al. Necrotizing enterocolitis is associated with Ureaplasma colonization in preterm infants. Pediatr Res (2011) 69(5 Pt 1):442-7. doi:10.1203/PDR. 0b013e3182111827

70. DeSilva NS, Quinn PA. Characterization of phospholipase A1, A2, C activity in Ureaplasma urealyticum membranes. Mol Cell Biochem (1999) 201(1-2):159-67. doi:10.1023/A:1007082507407

71. Quinn PA. Evidence of an immune response to Ureaplasma urealyticum in perinatal morbidity and mortality. Pediatr Infect Dis (1986) 5(6 Suppl):S282-7. doi:10.1097/00006454-198611010-00018

72. Quinn PA, Rubin S, Nocilla DM, Read SE, Chipman M. Serological evidence of Ureaplasma urealyticum infection in neonatal respiratory disease. Yale J Biol Med (1983) 56(5-6):565-72.

73. Menon R, Peltier MR, Eckardt J, Fortunato SJ. Diversity in cytokine response to bacteria associated with preterm birth by fetal membranes. Am J Obstet Gynecol (2009) 201(3):e1-6. doi:10.1016/j.ajog.2009.06.027

74. Aaltonen R, Heikkinen J, Vahlberg T, Jensen JS, Alanen A. Local inflammatory response in choriodecidua induced by Ureaplasma urealyticum. BJOG (2007) 114(11):1432-5. doi:10.1111/j.1471-0528.2007.01410.x

75. Manimtim WM, Hasday JD, Hester L, Fairchild KD, Lovchik JC, Viscardi RM. Ureaplasma urealyticum modulates endotoxin-induced cytokine release by human monocytes derived from preterm and term newborns and adults. Infect Immun (2001) 69(6):3906-15. doi:10.1128/IAI.69.6.3906-3915.2001

76. Reyes L, Reinhard M, Brown MB. Different inflammatory responses are associated with Ureaplasma parvum-induced UTI and urolith formation. BMC Infect Dis (2009) 9:9. doi:10.1186/1471-2334-9-9

77. Kjer-Nielsen L, Patel O, Corbett AJ, Le Nours J, Meehan B, Liu L, et al. MR1 presents microbial vitamin B metabolites to MAIT cells. Nature (2012) 491(7426):717-23. doi:10.1038/nature11605

78. Bastian M, Braun T, Bruns H, Rollinghoff M, Stenger S. Mycobacterial lipopeptides elicit CD4+ CTLs in Mycobacterium tuberculosis-infected humans. J Immunol (2008) 180(5):3436-46. doi:10.4049/jimmunol.180.5.3436

79. Gold MC, Cerri S, Smyk-Pearson S, Cansler ME, Vogt TM, Delepine J, et al. Human mucosal associated invariant $\mathrm{T}$ cells detect bacterially infected cells. PLoS Biol (2010) 8(6):e1000407. doi:10.1371/journal.pbio.1000407

Conflict of Interest Statement: The authors declare that the research was conducted in the absence of any commercial or financial relationships that could be construed as a potential conflict of interest.

Received: 30 September 2014; accepted: 21 November 2014; published online: 09 December 2014

Citation: Ireland DJ and Keelan JA (2014) The maternal serological response to intrauterine Ureaplasma sp. infection and prediction of risk of pre-term birth. Front. Immunol. 5:624. doi: 10.3389/fimmu.2014.00624

This article was submitted to Inflammation, a section of the journal Frontiers in Immunology.

Copyright (c) 2014 Ireland and Keelan. This is an open-access article distributed under the terms of the Creative Commons Attribution License (CC BY). The use, distribution or reproduction in other forums is permitted, provided the original author $(s)$ or licensor are credited and that the original publication in this journal is cited, in accordance with accepted academic practice. No use, distribution or reproduction is permitted which does not comply with these terms. 